\title{
Aspectos fenológicos, ecológicos \\ e de produtividade do Mapati (Pourouma cecropififolia Mart.)
}

\author{
Martha de Aguiar Falcão (') \\ Eduardo Lleras $\left(^{2}\right)$
}

\begin{abstract}
Resumo
Neste trabalho, são apresentados dados da fenologia, ecologia e produtividade do Mapati (Pourouma cecropiifolia Mart.). Na região de Manaus, a espéc!e floresce na época de maior precipitação pluviométrica (abril a junho) com a safra no final da seca e início da seguinte época de chuvas (outubro a janeiro). Cinco espécies de insetos visitantes foram observados, dos quais quatro, todos da família Apidae apresentaram quantidades significativas de pólen, sugerindo a não existência de um polinizador específico e sim de um síndrome de polinização. O número de flores variou entre 4500 e 14000 para as cinco árvores estudadas com taxa de formação de frutos muito alta $(91 \%$ aproximadamente). Existe uma correlação muito alta entre número de flores e outros parâmetros de produção tais como número de frutos imaturos $\left(r=0,999^{* *}\right)$, número de frutos maduros $\left(r=0,999^{* *}\right)$, e peso da safra $\left(r=0,988^{* *}\right)$, o que não é surpreendente, considerando o alto índice de polinização. Sugere-se, como no caso do Umari, que o número de flores está intimamente ligado com a capacidade energética da árvore e que existe um controle endógeno de número de frutos levados à maturação de maneira a manter um certo peso por fruto individual.
\end{abstract}

\section{INTRODUÇÃO}

Nos últimos anos, o crescimento populacional, especialmente nas áreas urbanas da Amazônia, tem levado a despertar um grande interesse na tecnificação da cultura e industrialização de espécies frutíferas tanto nativas quanto introduzidas.

Na região de Manaus, destacam-se as pesquisas que estão sendo realizadas pelo INPA, onde, além da implantação de um banco de germoplasma, estão sendo montados experimentos sobre melhoramento genético. Dentro dos trabalhos realizados, destacam-se os de
Clement et al. (1977), Pahlen (1978), Gondim (1978) e Kerr et al. (1979) .

Este trabalho, que continua a série iniciada com o Umari (Falcão \& Lleras, no prelo), visa a contribuir para o conhecimento da biologia do Mapati, colaborando assim com a ênfase que está sendo dada a esta espécie nativa pelo grupo de fruticultura do INPA.

\section{MATERIAL E MÉTODOS}

Inicialmente foram escolhidas 10 árvores, sendo cinco masculinas e cinco femininas, em dois locais: Sítio Rosa de Maio, Estrada Manaus-Itacoatiara $\mathrm{Km} 8$ a área verde do Tropical Hotel, Ponta Negra, Manaus.

Foram coletadas amostras testemunhas que estão depositadas no herbário do INPA sob o número de registro INPA. 77590 (Pourouma cecropiifolia, col. Martha Falcão, 215) .

As observações de campo foram realizadas semanalmente. As datas estimadas quanto ao início e ao término dos fenômenos fenológicos têm assim aproximação de \pm 6 dias .

Durante o período de floração, em cada árvore foram escolhidos 3 galhos, ao acaso, nos quais se fez a contagern das inflorescência e flores. Com a finalidade de estimar-se a quantidade de inflorescências e flores produzidas pela árvore, foram contados todos os galhos.

As flores foram dissecadas e comparadas com a descrição feita por Prance \& Silva (1975).

A fim de ter-se uma idéia de que as flores eram ou não autofecundadas, foram colocados envoltórios de filó de malhas milimétricas ou de morim em 10 inflorescências de cada árvore, dando um total de 50 envoltórios para a espécie.

(*) - Parte deste trabalho foi extraída da Tese defendida pelo primeiro autor para obtenção do grau de Mestre em Ciências Biológica.

(1) - Fundação Universidade do Amazonas - Manaus .

(2) - Instituto Nacional de Pesquisas da Amazôn!a Manaus 
Foi feito o estudo do pólen encontrado nas patas dos insetos com a finalidade de fazer-se uma comparação com o pólen da espécie visitada. Nos dois casos o método usado na preparação do pólen foi o da acetólise (Erdtman. 1960), seguido da montagem de grãos em gelatina glicerinada.

Para determinar-se os possíveis polinizadores da espécie, todos os insetos que visitavam as flores foram coletados, acondicionados e identificados pelo Dr. Norman Penny, do Departamento de Entomologia do INPA, Dr. Warwick Kerr e Dr. João Camargo, da Faculdade de Medicina de Ribeirão Preto.

Para estabelecer-se uma correlação entre a freqüência dos insetos nas árvores e a quantidade de pólen que eles carregam, foi feita a contagem padrão de 1.000 grãos de pólen por amostra .

No período de frutificaçãc, as contagens dos frutos foram feitas nos mesmos galhos em que foram contadas as inflorescências e flores. Tanto os frutos imaturos quanto os maduros que permaneciam nos galhos ou caídos embaixo de cada árvore foram contados com o objetivo de calcular-se a média dos frutos perdidos e da safra de cada espécie.

Foram pesados 500 frutos, ou seja, 50 frutos de cada árvore. Dos frutos submetidos à pesagem, foram retiradas as sementes, polpas e cascas, as quais foram pesadas, sendo que as sementes foram também contadas. Para as pesagens obtidas foi utilizada balança de precisão.

Foram feitas medidas do fuste, do diâmetro e da copa das árvores em estudo a fim de fazer-se uma correlação entre a idade e a produtividade dessas árvores.

Todos os resultados obtidos foram submetidos a diversos cálculos estatísticos, como: média aritmética, desvio-padrão, erro padrão da média, variância, coeficiente de variação, teste " $T$ ", teste d'Agostini, curtose, regressão linear e $X^{2}$.

As descrições botânicas das espécies foram baseadas nos trabalhos de Prance \& Silva (1975), Cavalcante (1976) e em observações pessoais.

\section{MAPATI}

\section{Pourouma cecropiifolia Mart.}

\section{CONSIDERAÇÕES GERAIS}

Segundo um relatório da NAS. National Academy Of Sciences (1975), "a exploração da espécie Pourouma cecropiifolia (Mapati) foi negligenciada pela ciência e pelo fato de nunca ter sido assunto nos estudos agronômicos, não houve tentativa para estabelecer sua cultura. Por esse motivo poucos são os trabalhos que se referem à composição química e ao valor nutritivo de seus frutos". Para a Amazônia, essas observações não são válides, visto que os caboclos de Tabatinga, Benjamim Constant, Letícia e lquitos plantam-na para exploração comercial e o INPA vem incrementando a produção (Kerr et al., 1979) .

Restrepo (1870 apud Patiño, 1963) estudou a biologia floral de Pourouma cecropiifolia. Ducke (1925) fez referências aos frutos, achando-os com sabor de uva e com casca apresentando, leve odor da salicilato de metila. Porto (1936) cita a procedência e distribuição geográfica, dando ênfase aos nomes vulgares. Ducke (1946) considerou-a como uma espécie muito cultivada entre os índios e civilizados da parte Ocidental da Amazônia, sobretudo nas fronteiras com Peru e Colômbia e ainda vizinhança de Iquitos. Le Cointe (1947) informou que os frutos são parecidos com uva e comumente usados para vinho; Correa (1952) descreveu-a sucintamente e citou uma série de nomes vulgares; Fonseca (1954) também anota que os frutos são comestiveis e de sabor adocicado e quando fermentados dão bebidas vinhosas e anotando ainda que é conhecida com os nomes de cucura, umbaúba (Brasil) e uvilla, no Peru. A expedição de Quesada em 1569 (Patiño, 1963) fez um relato sobre os jesuitas Cassani e Rivero que deram uma valiosa notícia descritiva sobre os aspectos botânicos de Pourouma cecropiifolia. Patiño (1963) fez uma excelente revisão bibliográfica sobre várias espécies nativas incluindo a uvilla como é conhecida no Peru e na Colômbia. Anotou que a espécie toi encontrada nativa na Colômbia sendo cultivada descie a época pré-hispánica. Gutierrez, (1969) estudou-a no Peru, tratando de aspectos botâ- 
nicos, fenológicos e ensaios de germinação. Prance \& Silva (1975) fizeram uma descrição geral englcbando aspectos botânicos, fitogeográficos, fenológicos e usos na cidade de Manaus. Cavalcante (1976) fez observações, sobre o valor econômico, incluindo-a entre as frutas comestiveis do Pará.

\section{a) Aspectos Botânicos}

Nome científico - Pourouma cecropiifolia Mart. (Fig. 1a, b, c e d);

Nomes vulgares $\left({ }^{3}\right)-$ Brasil: Matapi, Cucura, Umbaúba de cheiro, Umbaúba de vinho, Amaitem, Imbaúba-mansa, Imbaúba de Vinho, Tararanga preta, Imbaúbarana, Sucuuba, Uva de mata;

- Colômbia: Camuirro (índios) Sirpe, caima, caimarón (ou camairỏn), uva caimarona (Peréz., 1956, apud Patiño, 1963), Hiye, Joyahiye (Caquetá-Putumayo), (Jimenez, 1904, apud Patiño, 1963):

- Guiana Francesa: Puruma, em Caribe (Aublet 1775, II, 892);

- Peru: Uvilla;

\section{Família: Moraceae}

Árvore de aproximadamente 3 a $15 \mathrm{~m}$ de altura, copa frondosa e esgalhada; folhas simples, alternas, pecioladas, com estípulas laterais; lâmina palmatilobada, coriácea; verde-clara na face inferior, verde-escura na face superior; margem inteira; inflorescências panículas axilares; flores unissexuais, actinomorfas, apopétalas, monoclamídeas, isostêmones; receptáculo cupuliforme; pedicelos cilíndricos; tépalas 4, livres, pubescentes, castanho-escuros; flores masculinas com 4 estames, livres, filetes curtos, anteras rimosas, subglobosas; flores femininas com perianto carnoso, cupuliforme; carpelo de 1 ovário súpero, oval, glabro externamente, unilocular, uniovular; placentação basal; óvulo ortótropo; estilete terminal; estígma 1; fruto, drupa ovado globosa; epicarpo fibroso; verde quando jovem, violáceo quando maduro; polpa gelatinosa, levemente adocicada, semente 1 , ovada, dura.

\section{b) Distribuição Geográfica e Habitat}

No Brasil, está distribuída por toda a Amazônia Ocidental, no Estado do Amazonas (Manaus, Benjamim Constant e São Gabriel da Cachoeira) e Acre (Cavalcante, 1976). No Peru (lquitos) e na Colômbia (Letícia), (Ducke, 1946; Le Cointe, 1947 e Prance \& Silva, 1975).

Ocorre nas matas de terra firme.

\section{c) Usos}

Os frutos são comestíveis e quando fermentados produzem um saboroso vinho. A árvore é comumente cultivada pelos indígenas e também pode servir para ornamentação de jardins. Os frutos são comercializados pelos caboclos de Tabatinga, Benjamim Constant (comum. pessoal Kerr) e também bastante conhecidos no Peru e Colômbia (Patiño, 1963).

\section{d) Características Químicas}

Collazos et al (1957) realizaram análise química de fruto de Mapati. Os dados são apresentados a seguir:

TABELA 1 - Nutrientes do fruto maduro do Mapati contido em $100 \mathrm{~g}$ de polpa.

\section{Componentes maiores/g}

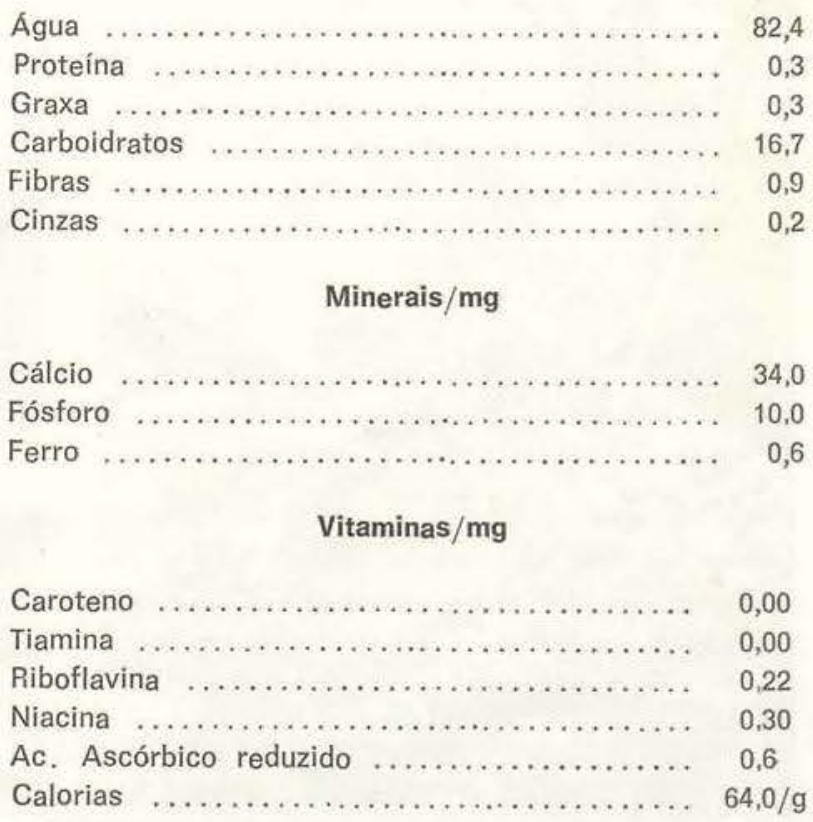

(3) - Todos os autores aqui mencionados são citados de Patiño (1963). 
Componentes maiores $\%$ peso sêco

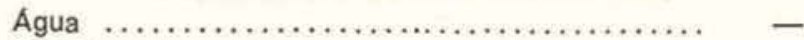

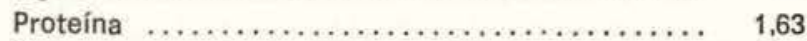

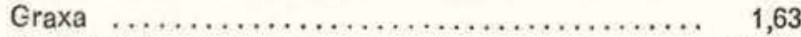

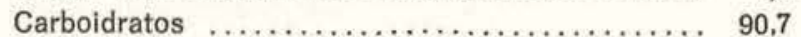

Fibras ............................... 4,89

Cinzas $\ldots \ldots \ldots \ldots \ldots \ldots \ldots \ldots \ldots \ldots \ldots \ldots \ldots \ldots \ldots \ldots \ldots, 1,08$

Os dados químicos indicam que em peso total, a maior parte do fruto e água e o peso seco estão quase todos representados por car. boidratos. Descie o ponto de vista industrial, a espécie parece muito aproveitável para fabricação de vinhos e geléias.

FENOLOGIA

\section{a) Floração}

Durante o período da floração, foi verificado que das 10 árvores em estudo, cinco (5) eran masculinas e cinco (5) femininas.
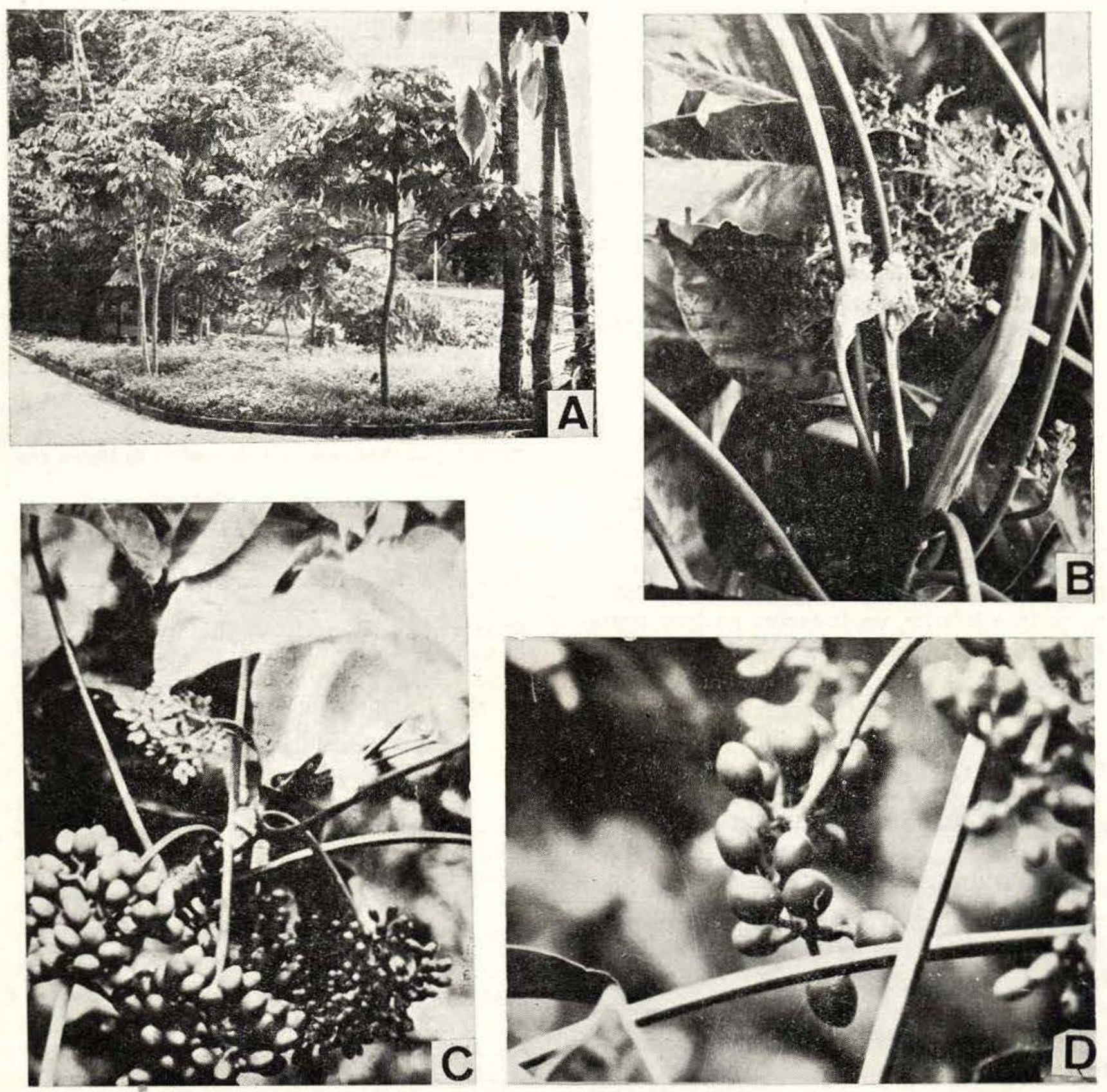

Fig. 1 - Pourouma cecropiifolia. A, árvore jovem; B, detalhes da inflorescência; C, frutos imaturos e D, frutos maduros. 


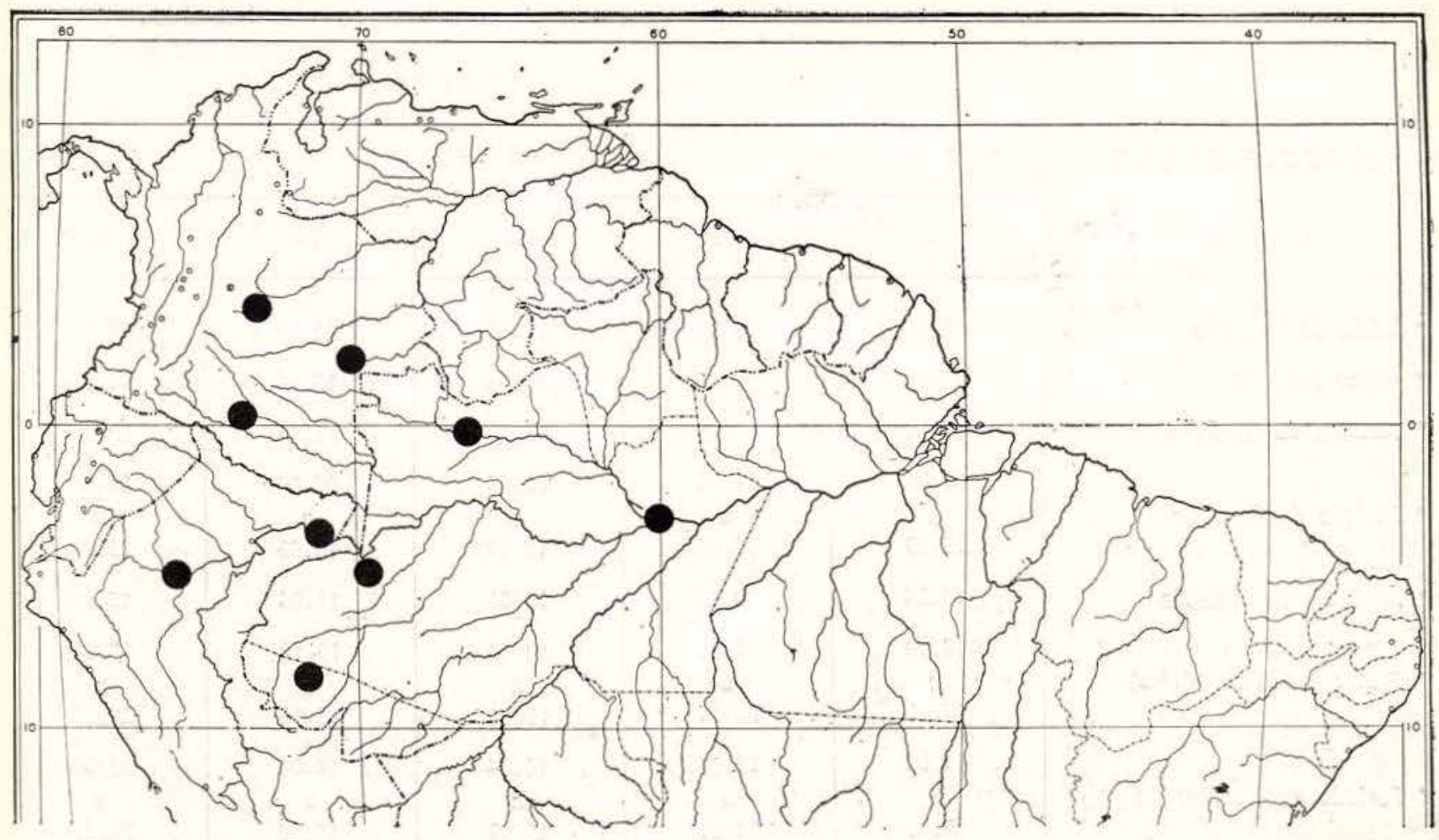

Fig. 2 - Distribuição geográfica conhecida de Pourouma cecropiifolia.

Gutierrez (1969) anota para o Peru que o Mapati floresce em julho e agosto, com os frutos amadurecendo entre setembro e novembro. Prance \& Silva (1975) indicam que a espécie floresce e frutifica durante todo o ano, sendo que Cavalcante (1976) anota que os frutos aparecem nas feiras de Manaus nos primeiros meses do ano.

No presente estudo, as árvores femininas floraram aproximadamente entre 2 de abril a 15 de maio (árvores 1, 3 e 4 sítio Rosa de Maio) ou entre a 26 de abril e 16 de junho (árvores 2 e 5 - Tropical Hotel), sendo o período de floração em média de aproximadamente 47 dias. Dada a pouca diferença em dias de um local ao outro, admite-se apenas um período de floração. Nas árvores de flores masculinas, a floração foi esporádica durante o ano, porém com maior intensidade no período coincidente com a floração das árvores femininas (Tabela 2) .

O período de maior floração foi durante a época chuvosa para a região de Manaus, cessando com a época da seca (Fig. 3) .

\section{b) Frutificação}

Pelo fato de somente 5 das 10 árvores, em estudo, de Pourouma cecropiifolia apresentarem flores femininas, os dados obtidos na frutificação são apresentados só para 5 árvores. 0 desenvolvimento dos frutos ocorreu entre 14 de abril a 22 de janeiro do ano seguinte. Todavia, o período da safra foi de 18 de outubro a 22 de janeiro tanto no sítio Rosa de Maio quanto no Tropical Hotel (Tabela 2).

Nas 5 árvores, a duração em dias do inícic de floração ao início de frutificação foi em média de 15 dias, aproximadamente; do início de frutificação a máxima floração foí, em média, 3 dias; a duração da frutificação teve média de 248 dias e do início da frutificação ao início da safra, a duração foi, em média, aproximadamente 187 dias (Tabela 3).

c) Mudança Foliar.

Ocorreu entre 6 de janeiro a 25 de fevereiro, com uma duração aproximada de 50 dias, durante a época chuvosa. 
TABELA 2 - Pourouma cecropiifolia. Dados fenológicos básicos 1977-1978. Árvores femininas.

\begin{tabular}{|c|c|c|c|c|c|}
\hline \multirow{3}{*}{ ESPECIFICAÇ AO } & \multicolumn{5}{|c|}{ DIAS - MESES } \\
\hline & \multicolumn{5}{|c|}{ ARVORES } \\
\hline & 01 & 02 & 03 & 04 & 05 \\
\hline - Início da floração & 02.04 & 26.04 & 02.04 & 02.04 & 26.04 \\
\hline - Maior floração & 15.04 & 06.05 & 15.04 & 15.04 & 06.05 \\
\hline - Término da floração & 15.05 & 16.06 & 15.05 & 15.05 & 16.06 \\
\hline - Período da floração & $\begin{array}{c}02.04 \\
a \\
15.05\end{array}$ & $\begin{array}{c}26.04 \\
a \\
16.06\end{array}$ & $\begin{array}{c}02.04 \\
a \\
15.05\end{array}$ & $\begin{array}{c}02.04 \\
a \\
15.05\end{array}$ & $\begin{array}{c}26.04 \\
a \\
16.06\end{array}$ \\
\hline - Início da frutificaçāo & 14.04 & 15.05 & 14.04 & 14.04 & 15.05 \\
\hline - Frutos maduros (Safra) & $\begin{array}{c}18.10 \\
a \\
15.12\end{array}$ & $\begin{array}{c}16.11 \\
a \\
22.01\end{array}$ & $\begin{array}{c}18.10 \\
a \\
15.12\end{array}$ & $\begin{array}{c}18.10 \\
a \\
15.12\end{array}$ & $\begin{array}{c}16.11 \\
a \\
22.01\end{array}$ \\
\hline - Período da frutificação & $\begin{array}{c}14.04 \\
a \\
15.12\end{array}$ & $\begin{array}{c}15.05 \\
a \\
22.01\end{array}$ & $\begin{array}{c}14.04 \\
a \\
15.12\end{array}$ & $\begin{array}{c}14.04 \\
a \\
15.12\end{array}$ & $\begin{array}{c}15.05 \\
a \\
22.01\end{array}$ \\
\hline - Mudança foliar & $\begin{array}{l}06.01 \\
a \\
30.01\end{array}$ & $\begin{array}{c}01.02 \\
a \\
25.02\end{array}$ & $\begin{array}{c}06.01 \\
a \\
30.01\end{array}$ & $\begin{array}{c}06.01 \\
a \\
30.01\end{array}$ & $\begin{array}{c}01.02 \\
a \\
25.02\end{array}$ \\
\hline * Localização das árvores & Rosa de Maío & $\begin{array}{c}\text { Ponta Negra } \\
\text { (Hotel } \\
\text { Tropical) }\end{array}$ & & & $\begin{array}{c}\text { Ponta Negra } \\
\text { (Hotel } \\
\text { Tropical) }\end{array}$ \\
\hline
\end{tabular}

d) Insetos Visitantes

Durante as observações, foram coletadas 5 espécies de insetos que visitam as flores de Pourouma cecropiifolia. Dentre estas, quatro são abelhas que fazem visitas com grande freqüência e duas, formigas que vivem constantemente nas árvores.

As abelhas fazem as visitas preferencialmente na parte da manhã ( 6 às $13 \mathrm{hs}$ ) e esporadicamente pela parte da tarde, visitando inicialmente as flores masculinas, coletando o pólen com grande agilidade e voando em seguida para as inflorescências femininas onde permanecem rapidamente. As flores visitadas e presumivelmente polinizadas mudam a coloração de amarelo claro para marrom, o que permite determinar com grande facilidade o índice de visitas.
TABELA 3 - Pourouma cecropiifolia. Duração em dias dos principais eventos durante a frutificação.

\begin{tabular}{l|c}
\hline \multicolumn{1}{c|}{ Árvores } & 1 a 5 \\
\hline $\begin{array}{l}\text { Eventos } \\
\text { Início de floração }\end{array}$ & 15,8 dias $\pm 3,8$ \\
$\begin{array}{l}\text { Início de frutificação } \\
\text { Início de frutificação }\end{array}$ & $3,4 \pm 6,0$ \\
$\begin{array}{l}\text { Máxima floração } \\
\text { Início de frutificação } \\
\text { Final de floração }\end{array}$ & $32,4 \pm 0,55$ \\
\hline $\begin{array}{l}\text { Duração da floração } \\
\text { Duração da frutificação }\end{array}$ & $32,50 \pm 16,26$ \\
\hline $\begin{array}{l}\text { Início de frutificação } \\
\text { a }\end{array}$ & $187,2 \pm 1,09$ \\
\hline
\end{tabular}


TABELA 4 - Espécies de insetos encontrados nas árvores de Pourouma cecropiifolia. Quantidades de grãos de pólen encontrados nas patas dos insetos.

\begin{tabular}{|c|c|c|c|c|}
\hline Ordem & Fa milia & Es pécie & $\begin{array}{l}\text { Grão pólen } \\
\text { p/amostra }\end{array}$ & Col/N.॰ coleta \\
\hline Hymenoptera & Apidae & Oxitrigona obscura (Friese) & 340 & M. Falcäo. 2 \\
\hline Hymenoptera & Apidae & Trigona dellatarreana (Friese) & 1.260 & M. Falcăo, \\
\hline Hymenoptera & Apidae & Trigona sp. & 1.345 & M. Falcão, 1 \\
\hline Hymenoptera & Apidae & Não identificada & 596 & M. Falcão, 61 \\
\hline Hymenoptera & Formicidae & Camponotus sp. & 0 & M. Falcāo, 100 \\
\hline
\end{tabular}

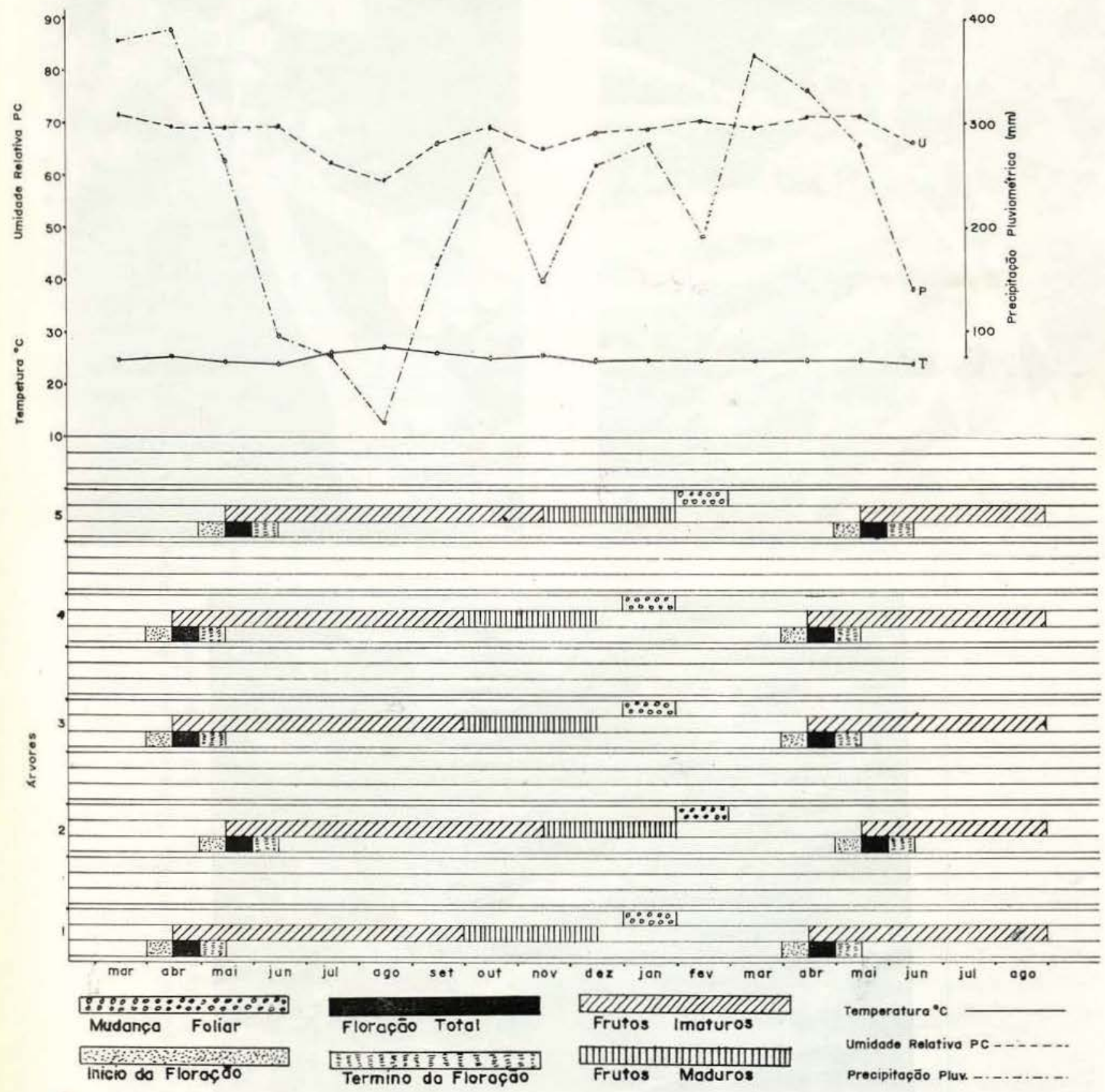

Fig. 3 - Pourouma cecropiifolia. Quadro geral de floração, frutificação, produção e queda de folhas. Acima, dados climatólogicos para a área de Manaus; abaixo dados fenológicos (Ribeiro, 1977). 
Duas espécies de Trigonas Trigona dellatarreana (Friese) e Trigona sp., tiveram altas quantidades de pólen nas patas e corpo, sendo Oxytrigona obscura (Friese) e outra Apidae não identificada também apresentaram bastan-

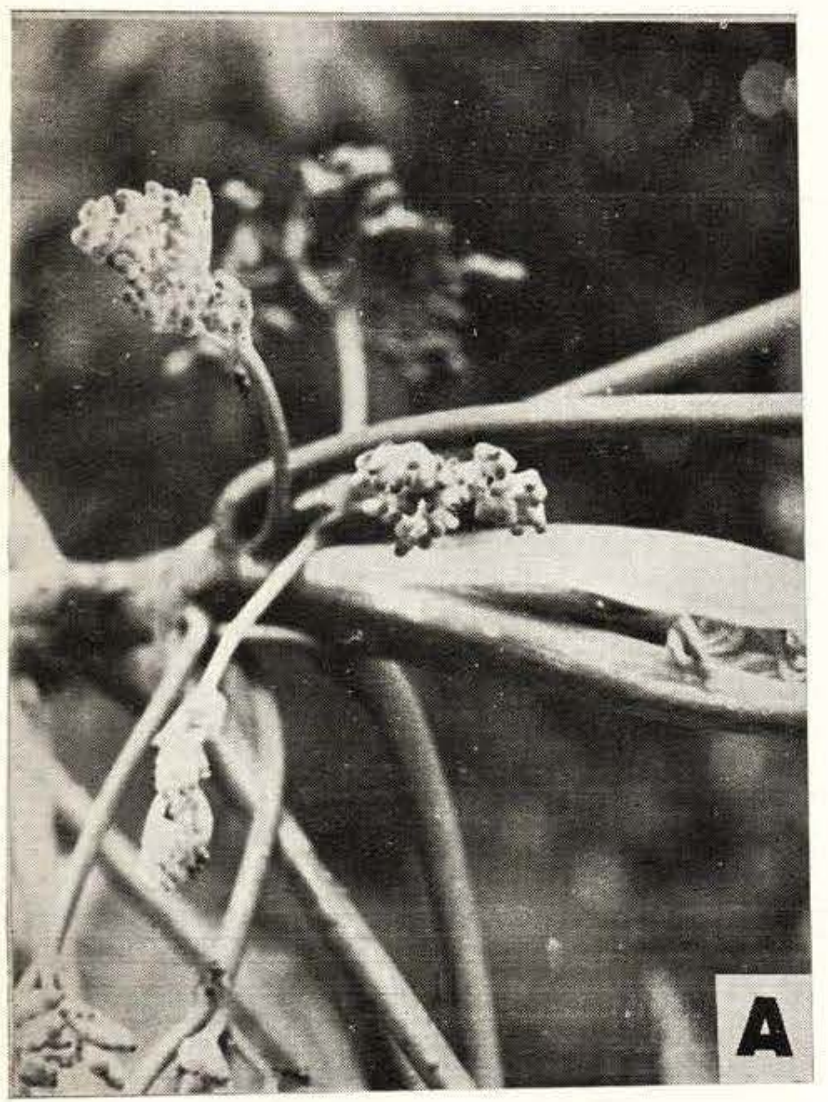

te pólen, porém menos que as duas acima mencionadas.

Protegendo-se as flores com sacos de filó para determinar-se a possibilidade de poiinização anemófila, verificou-se que nenhuma flor

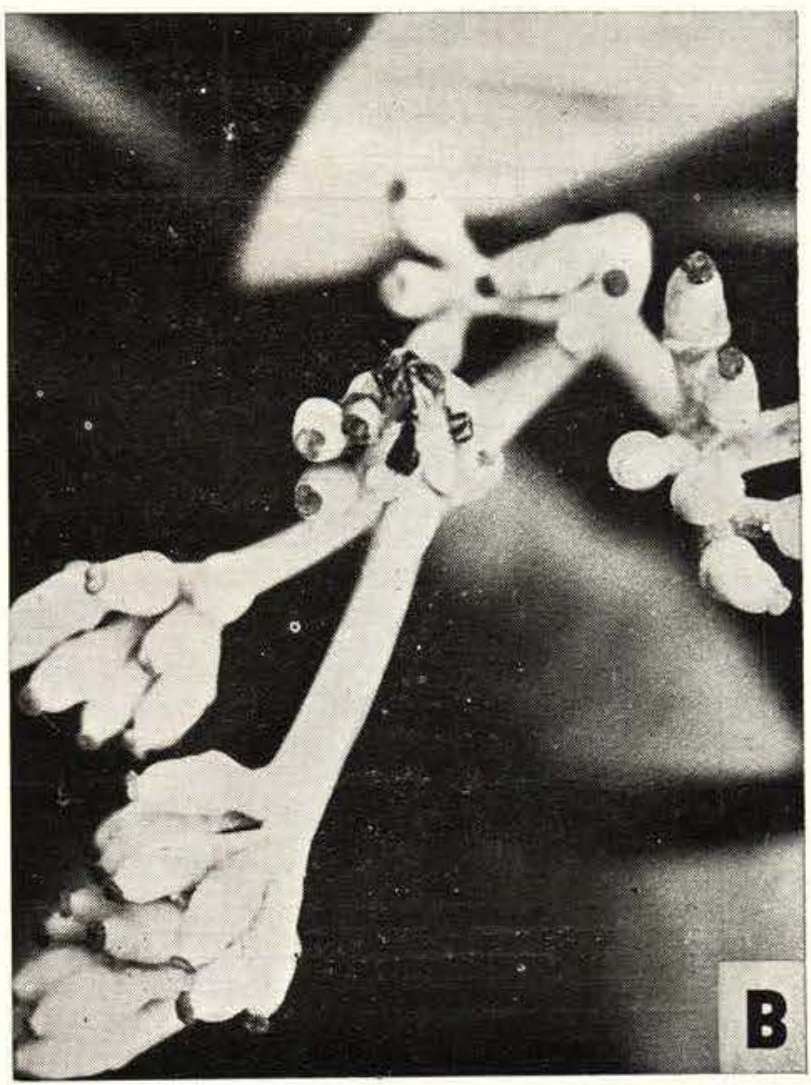

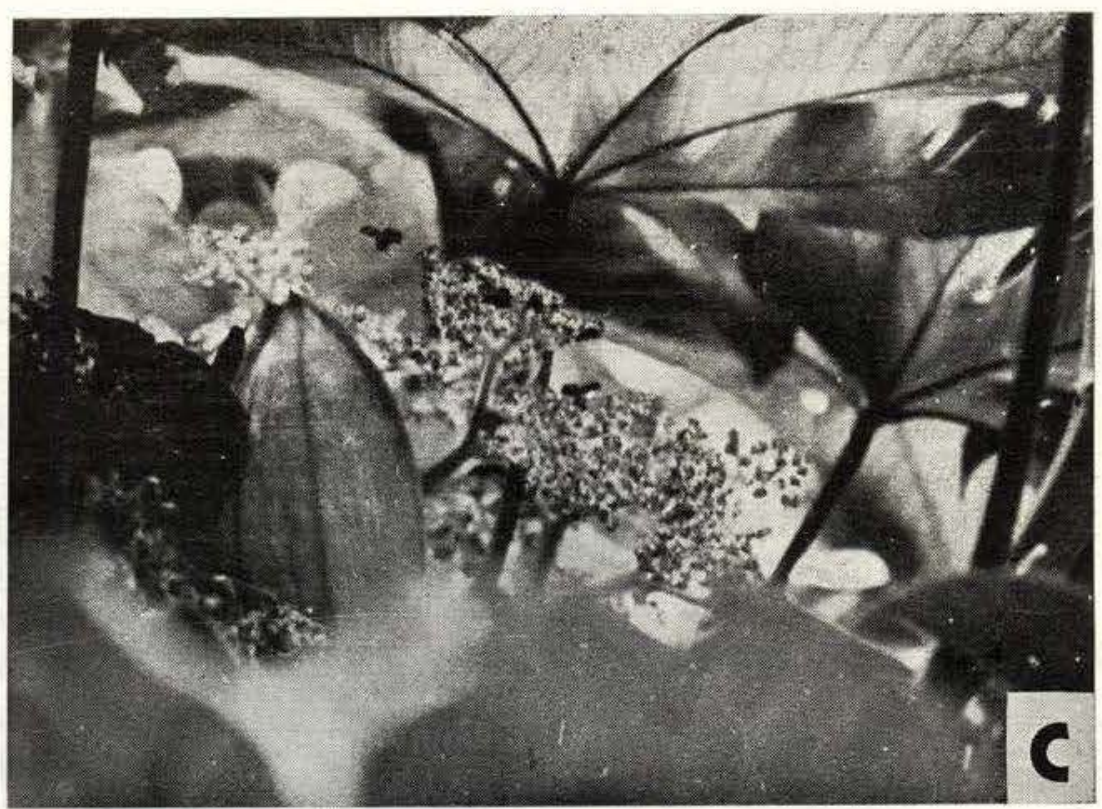

Fig. 4 - Insetos visitantes em Pourouma cecropiifolia. A, Camponctus sp.; B, C, Trigona sp. 
TABELA 5 - Pourouma cecropiifolia. Média dos dados de produçăo incluindo-se, entre outros, número de flores, frutos imaturos e maduros e peso da safra. Árvores 1, 3 e 4 sítio Rosa de Maio; 2 e 5 Tropical Hotel.

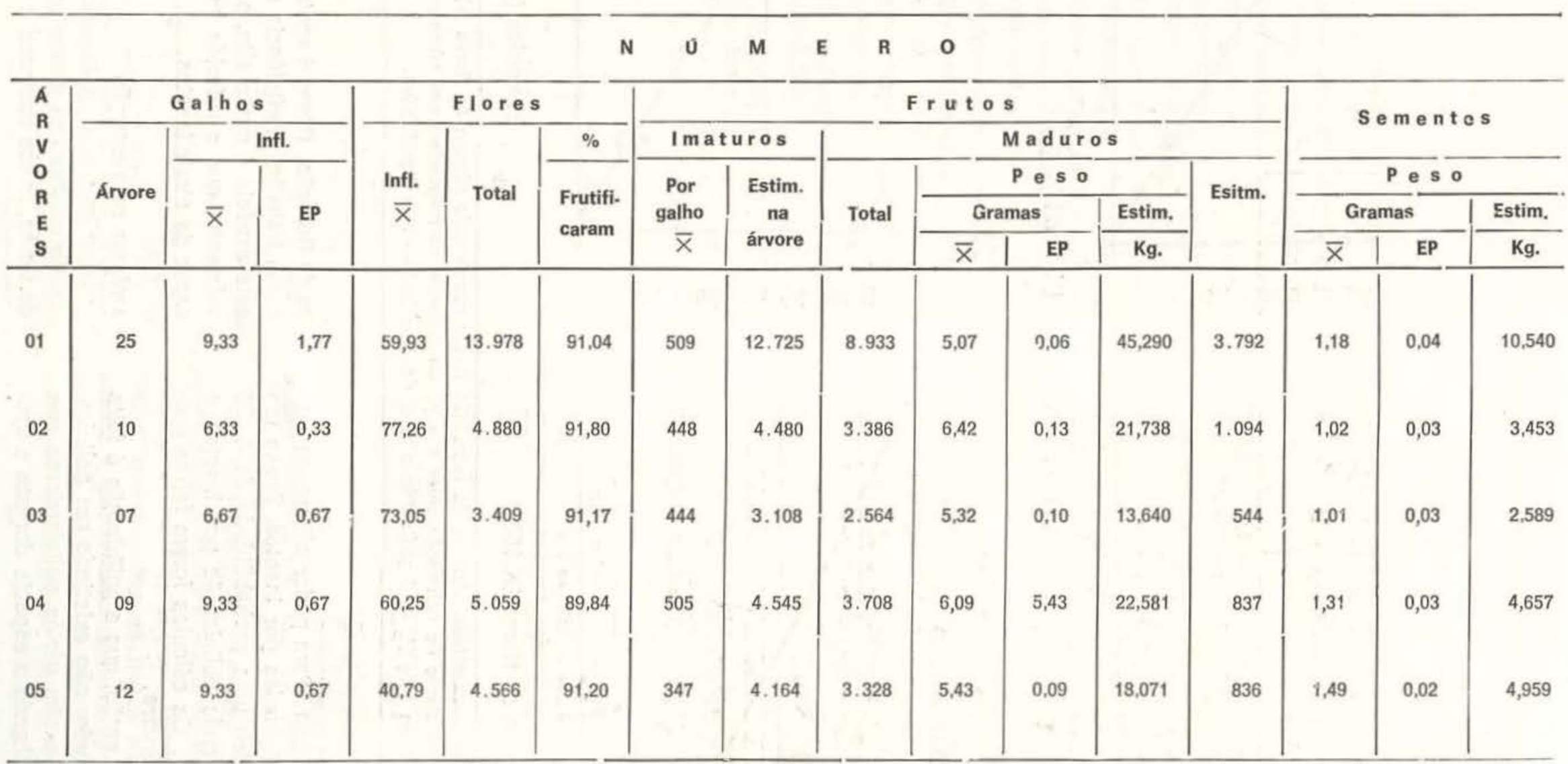



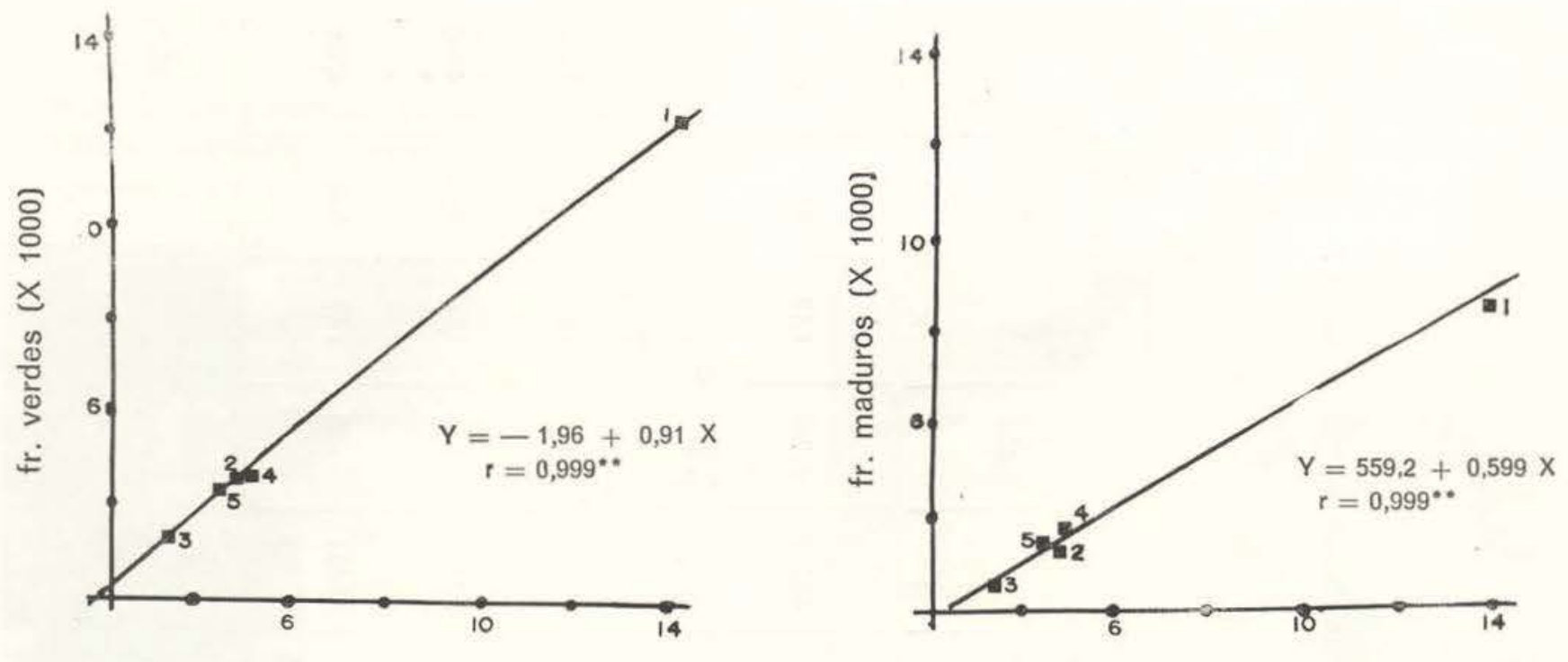

número de flores (X 1000)

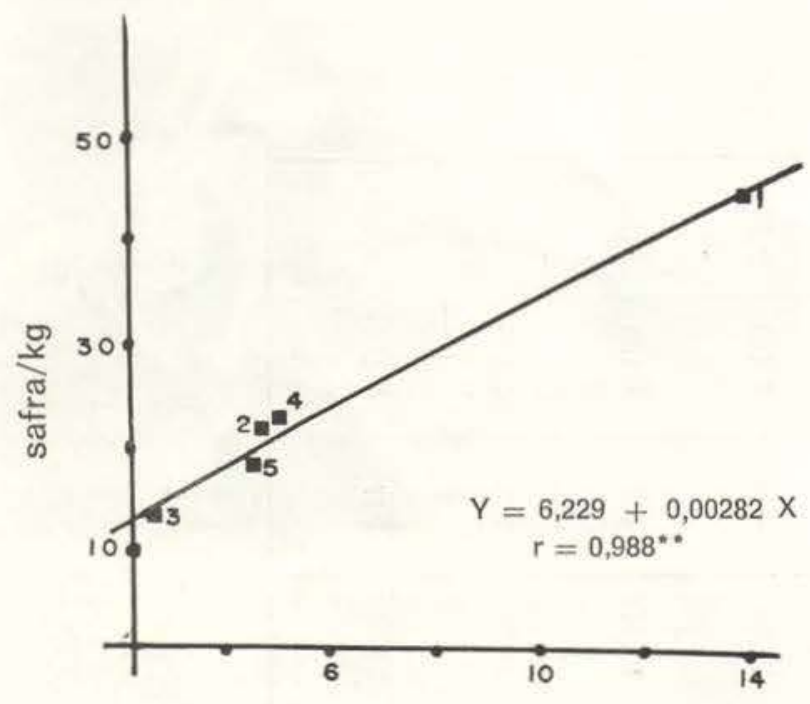

número de flores (X 1000)

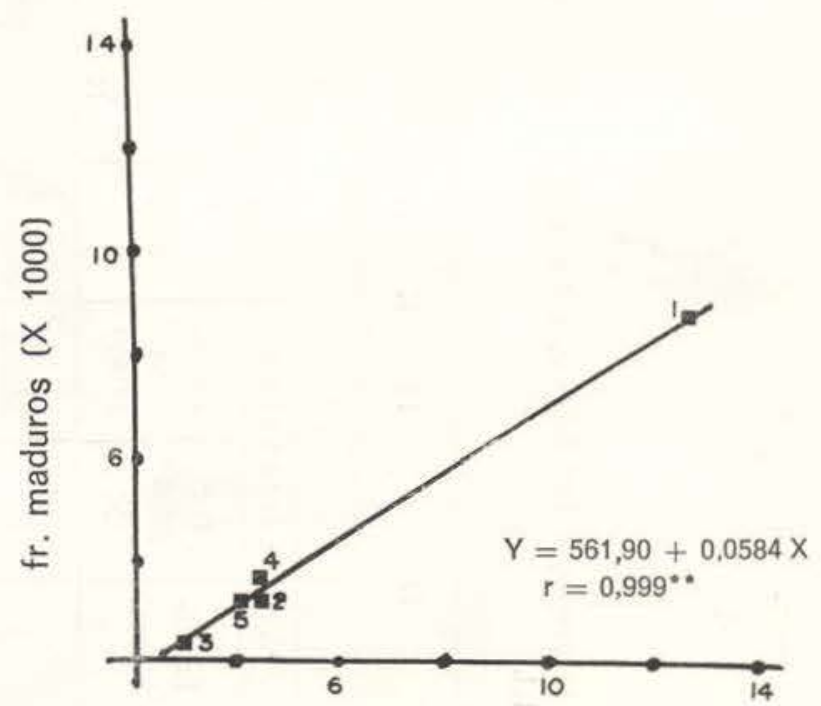

fr. verdes (X 1000)

Fig. 5 - Pourouma cecropiifolia. Análise de regressão lin ear comparando número de flores $(x)$ com outros dados de produçăo $(y) ; r=$ coeficiente de correlaçã̃o entre $x$ e $y$. Os números correspondem aos números das árvores. $(\cdots)-$ Significativo a nível de $1 \% ;\left({ }^{*}\right)$ - Significativo a nível de $5 \%$; (ns) - Năo Significativo.

protegida frutificou. Para poder afirmar-se que estas eram polinizadas por insetos, fez-se um teste $x^{2}$, que deu uma probabilidade de 0,999 de estar ocorrendo polinização por insetos e não pelo vento. Os cálculos foram feitos apenas para uma árvore.

Conclui-se, então, que a polinização é feita por abelhas, porém não existindo um polinizador específico e sim vários polinizadores que estão compartilhando a espécie durante a épo- ca de floração. Como é anotado, em outra parte deste trabalho, a eficiência de polinização para esta espécie é muito alta, o que sugere, possivelmente, que a referida espécie é altarnente capaz de atrair insetos.

\section{ANÁLISE DE PRODUÇÃo}

As médias dos dados básicos de produção de flores, frutos imaturos e maduros, percenta- 
gens de flores que frutificaram, peso de safra e peso das sementes, encontram-se na Tabela 5.

Os resultados apresentados na figura 4 mostram as análises de regressão linear, comparando-se o número de flores produzidas com o número de frutos imaturos, número de frutos madiros, peso da safra e frutos perdidos. Como no caso do Umari, houve uma grande correlaçăo entre número de flores e outros parâmetros da produção, o que parece lógico, considerando-se que a percentagem de flores que frutificaram foi de $91 \%$, surgindo um mecanismo de polirização muito eficiente (Tabela 5) .

A produção média das 5 árvores foi de $24,26 \pm 12,3 \mathrm{~kg}$ de frutos e, considerando-se que $26,02 \pm 4,5 \%$ destes representados por polpa. significa que, em média, $6,3 \mathrm{~kg}$ de polpa por árvore são aproveitáveis.

Comparando-se o número de flores e o número de frutos imaturos estimados, os coeficientes de correlação das cinco árvores femininas apresentaram correlação muito alta $(r=0,999)$. Os índices de correlação entre número de flores e frutos maduros foram também extremamente altos $(r=0,999)$.

As correlações entre peso dos frutos e o diâmetro das árvores, altura do fuste, altura

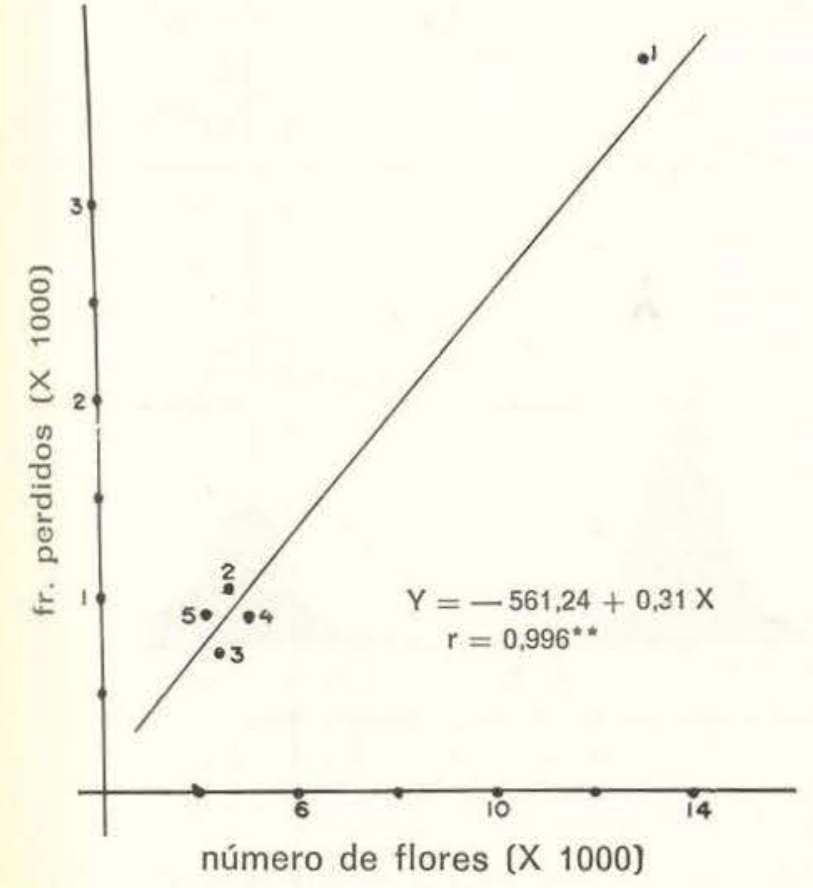

Fig. $6 *-$ Pourouma cecropiifolia. Regressão linear comparando o número de flores $(x)$ e o número de irutos perdidos $(y)$.
TABELA 6 - Pourouma cecropiifolia. Tamanho das árvores estudadas considerando-se diâmetro do fuste à altura do peito, altura total e idade das mesmas.

\begin{tabular}{l|c|c|c|c|c}
\hline Local & $\begin{array}{c}\text { Árvo- } \\
\text { re } \\
(\mathrm{cm})\end{array}$ & $\begin{array}{c}\text { Diâme- } \\
\text { tro } \\
(\mathrm{m})\end{array}$ & $\begin{array}{c}\text { Altura } \\
\text { do } \\
\text { Fuste } \\
(\mathrm{m})\end{array}$ & $\begin{array}{c}\text { Altura } \\
\text { Total }\end{array}$ & $\begin{array}{c}\text { Idade } \\
(\text { anos })\end{array}$ \\
\hline Tropical Hotel & 02 & 5,10 & 2,20 & 3,40 & 4 \\
Tropical Hotel & 05 & 5,57 & 1,50 & 2,80 & 4 \\
Rosa de Maio & 01 & 8,28 & 350 & 5,50 & 9 \\
Rosa de Maio & 03 & 7,01 & 2.00 & 4,00 & 9 \\
Rosa de Maio & 04 & 6,69 & 3,00 & 4,10 & 9 \\
\hline
\end{tabular}

da copa, altura total ou idade das mesmas não foram significativas.

$\mathrm{O}$ peso das sementes das árvores, individualmente tomadas, mostra a possibilidade de ter-se um gene maior controlando o peso, tentativamente se oferece a hipótese de que as árvores 1 e 4 sejam heterozigotos, produzindo 2 pesos de sementes, a 2 e 3 produzindo sementes leves e a 5 produzindo sementes pesadas. Fazemos esta sugestão, dada a importância agronômica de frutos com sementes menores que, também, são as mais leves (Fig. 6) .

As correlações entre número de flores $\mathrm{e}$ safra $(r=0,988)$, frutos imaturos com frutos maduros $(r=0,999)$ e número de flores com frutos perdidos $(r=0,996)$ todas foram significativas, ao nível de $1 \%$. Entretanto a correlação do peso da safra com a polpa não foi significativa $(r=0,53)$.

Em termos gerais, a situação observada com o Mapati é a mesma já discutida para o Umari (Falcão \& Lleras, 1980), existindo grande correlação entre o número de flores e outros parâmetros de produção. O alto índice de correlação entre número de flores e frutos maduros $(r=0,999)$ sugere, como no caso do Umari, que a perda de frutos não ocorre, ao acasc, e sim de uma maneira proporcional ao número de flores produzidas. De maneira semelhante, a correlação entre o número de flores e o peso da safra $(r=0,988)$ sugere uma 
alta correlação entre o consumo energético utilizado para produzir flores e a energia disponivel para produção da massa energética de safra.

A correlação entre frutos verdes e maduros foi, como era de esperar-se, muito alta $(0,999)$. o que evidencia que a perda de frutos não é fortuita, existindo, como no caso do Umari, um excess $\sigma$ de frutos formados com relação à dis- ponibilidade energética da árvore para levá-los até à maturação.

A grande diferença entre o Mapati e o Umari é que o primeiro apresenta índices de polinização muito altos (aprox. 90\%) e o segundo apresenta índices bem baixos (entre 4 a $9 \%$ ) . O comportamento similar ao comparar o número de flores com os outros parâmetros de pro-

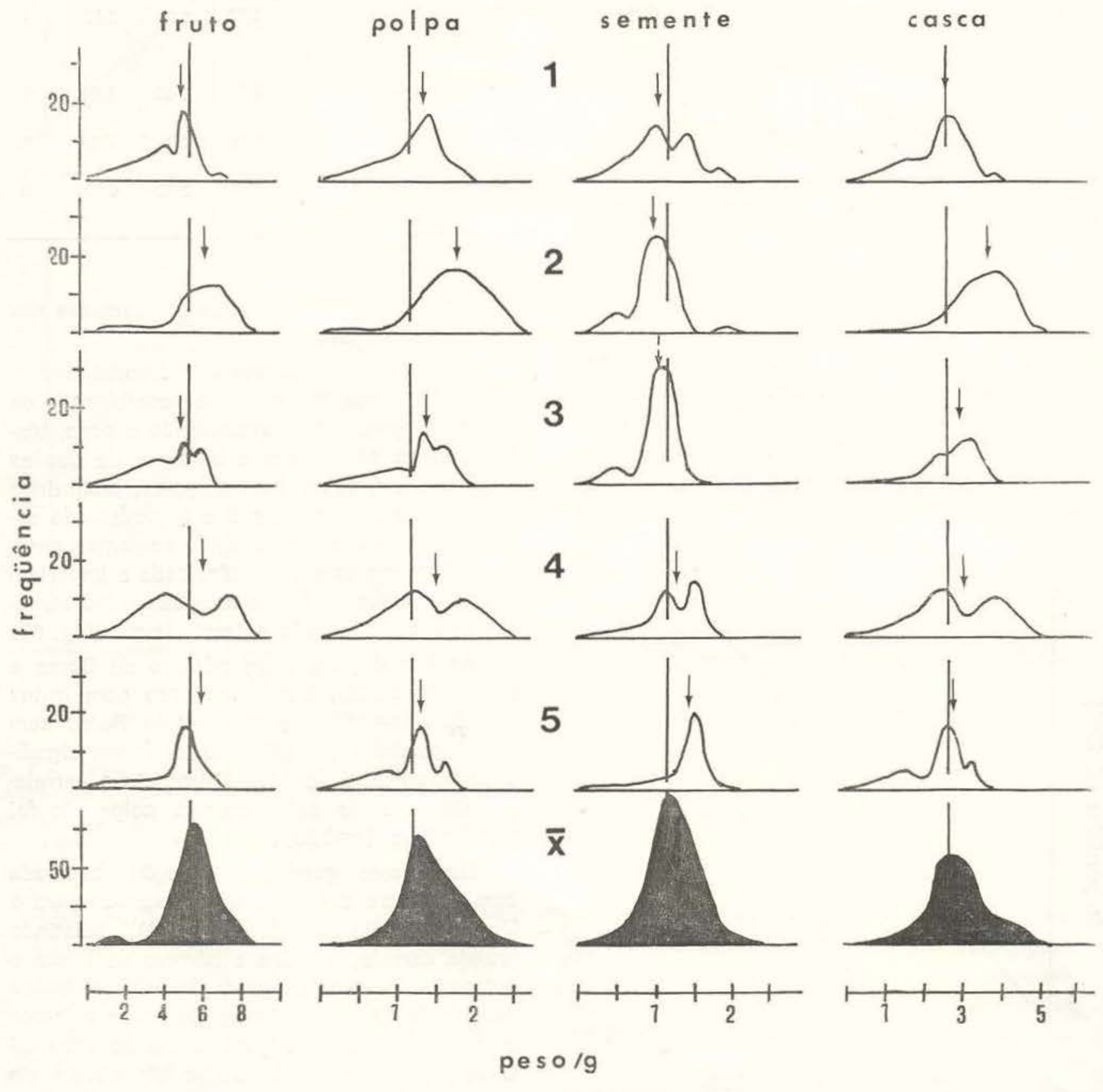

Fig. 7 - Poûrouma cecropiifolia. Frequêencia de pesos de fruto total, polpa e sementes das cinco árvores femininas, e das médias das mesmas. A linha que atravessa os graficos representa a média das médias; a seta em cada gráfico representa a média do mesmo. 
dução para as duas espécies, que, além de serem de duas familias filogeneticamente distantes, apresentam mecanismo de fecundação bem diferentes, sugere a existência de uma série de processos metabólicos comuns de amplo espectro com relação ao controle de floração, frutificação e peso de safra.

Certamente, a grande relaçăo entre queda (aborto) de frutos e número de flores $(r=0,996)$ sugere um processo endógeno e não um processo controlado por fatores externos de maneira semelhante à já discutida para o Umari.

Como no caso do Umari, serão precisas muito mais pesquisas para elucidar possíveis processos envolvidos no controle dos fenômenos acima discutidos e suas relações com fatores ambientais como nutrientes e outros.

\section{Agradecimentos}

Agradecemos, de maneira muito especial, a revisão crítica do manuscrito, sugestões e apoio a Warwick Estevam Kerr, Maria Lucia Absy, Herbert Otto Rogert Shubart, Angela Maria Conte Leite, Lea Maria Medeiros Carreira, Algenir Suano da Silva e João Chrysostomo de Oliveira, assim como a todos as outras pessoas que colaboraram direta ou indiretamente com este trabalho.

No trabalho de campo, somos muito gratos a Osmarino Santos Monteiro que sempre nos ajudou com eficiente disposição.

\section{SUMMARY}

Data on the phenology, ecology and productivity of Mapati (Pourouma cecropiifolia Mart.) are presented here. In the Manaus region the species flowers at the height of the rainy season (April to June) with the crop at the and of the dry season and beginning of the next rainy season (October to January). Five species of insects were found visiting the flowers, of which four, all of them Apidae, had significant amounts of pollen. This suggests lack of pollination specificty. The number of flowers per tree varied between 4500 and 14000 for the five trees studied with a high fruit set $(91 \%)$. A very high correlation was found between number of flowers and other production parameters such as number of green fruit $\left(r=0,999^{\circ *}\right)$, number of mature fruit $\left(r=0,999^{* *}\right)$ and crop weight $\left(r=0,988^{* *}\right)$. It is suggested that the number of flowers is intimately linked with the energetic capacity of the tree, and that the number of fruit reaching maturity is controlled endogenously in such a way as to maintain sertain standards for individual fruit weight.

\section{BIBLIOGRAFIA}

Cavalcante, P.B.

1976 - Frutas Comestiveis da Amazônia. 3 ed. Belém, INPA, $166 \mathrm{p}$.

Clement, C.R.; Kerr, W.E.; Weber, H.; Freitas, E.; Arkoll, David E.; Ranzani, G. \& Pahlen, E. von der 1977 - Ecologia e Fruticultura da Amazônia In: Seminário de Fruticultura, Manaus; (mimeografado, a0 p. (no prelo).

Collazos, C.Y. et al.

1957 - Composición de alimentos Peruanos. Lima, Ministério de Salud Pública. Instituto de Nutrición, 2. ${ }^{\text {a }}$ ed. 1957, 37 p. Apud Patiño (1963).

Correa, Pio

1952 - Dicionário das Plantas Úteis do Brasil e das Plantas Exóticas Cultivadas. Rio de Janeiro, Serviç̧o de Inf. Agrícola. Vol. 5, $102 \mathrm{p}$.

DUCKE, A.

1925 - Plantes nouvelles ou peu Connues de la région amazonienne III. Arch, Jard, Bot., Rio de Janeiro, $4: 1-210$.

1946 - Plantas de Cultura pré-colombiana na Amazônia brasileira. Bol. Téc. Inst. Agron. Norte, Belém, (8): 1-24.

ERDTMAN, G.

1960 - The acetolysis method: - a revised description. Sv. Bot. Tidskn Lund, 54(4) : 561-664.

Falcão, M.A. \& Lleras, E.

1980 - Aspectos fenológicos, ecológicos e de produtividade do Umari (Poraqueiba sericea Tulasne). Acta Amazonica 10(3): 445-462.

FoNSECA, E.T.

1954 - Frutas do Brasil. Rio de Janeiro, Inst. Nac. Livro, $281 \mathrm{p}$.

GoNDIM, E.J.C.

1960 - Alguns Aspectos da Biologia Reprodutiva do Guaraná (Paullinia cupana var. sorbilis (Mart.) Ducke - Sapindaceae. Tese de Mestrado. INPA. Manaus-Am. 83 p.

Gutierrez, A.R.

1969 - "Espécies Frutales Nativos de la seiva del Peru". Estudo Botânico y de Propagación po semillas tesis pa obtar el titulo de Ing. Agro. Lima, Peru. 
Kerr, W.E.; Clement, C.R. \& Silva Filho, D.F.

1979 - Práticas de consequências genéticas que possibilitavam aos indios da Amazônia uma melhor adaptaçăo, as condiçōes ecológicas da Regiăo. (no prelo).

Le COINTE, P.

1947 - Amazônia brasileira III. Árvores e plantas úteis (indigenas e aclimatadas) 2 ed. $\mathrm{S}$. Paulo, Ed. Nac. 506 p.

NAS - National ACADEMy OF SCIENCES

1975 - Underexploited Tropical Plants With Promising Economic Value. National Academy of Sciences. Washington, D.C.

PAHLEN, EVA VON DER

1978 - Fruteiras para a Amazônia. Em "Introdução à Horticultura e Fruticultura no Amazonas". Ediçăo da Suframa. Manaus.
PАกกัก, V.M.

1963 - Plantas Cultivadas y Animales domésticos em América Equinoccial - Tomo I: Frutales. Imprenta Departamental, Cali. Colom. bia. $547 \mathrm{p}$.

PORTO, P.C.

1936 - Plantas indígenas e exóticas provenientes da Amazônia, Cultivadas no Jardim Botânico do Rio de Janeiro. Rodriguesia. Anno II (5) $194 \mathrm{p}$.

Prance, G.T. \& Silva, M.

1975 - Árvores de Manaus. INPA. Manaus, 312 p. RIBEIRo, M.N.G.

1977 - Boletim Meteorológico Mensal. Instituto Nacional de Pesquisas da Amazônia. Setor de Meteorologia. Manaus, $14 \mathrm{p}$.

(Aceito para publicaçāo em $22 / 6 / 80$ ) 